\title{
Effect of Seismic Risk on Lifetime Property Value
}

\author{
Keith A. Porter, ${ }^{\text {a) }}$ M.EERI, James L. Beck, ${ }^{\text {b) }}$ M.EERI, \\ Rustem V. Shaikhutdinov, ${ }^{\text {c) }}$ Siu Kui Au, ${ }^{d}$ Kaoru Mizukoshi, ${ }^{\text {e) }}$ \\ Masamitsu Miyamura, ${ }^{f}$ Hiroshi Ishida, ${ }^{e}$ ) Takafumi Moroi, ${ }^{\text {g) }}$ \\ Yasu Tsukada, ${ }^{\text {h) }}$ and Manabu Masudai)
}

We examine seismic risk from the commercial real estate investor's viewpoint. We present a methodology to estimate the uncertain net asset value $(N A V)$ of an investment opportunity considering market risk and seismic risk. For seismic risk, we employ a performance-based earthquake engineering methodology called assembly-based vulnerability (ABV). For market risk, we use evidence of volatility of return on investment in the United States. We find that uncertainty in $N A V$ can be significant compared with investors' risk tolerance, making it appropriate to adopt a decision-analysis approach to the investment decision, in which one optimizes certainty equivalent, $C E$, as opposed to $N A V$. Uncertainty in market value appears greatly to exceed uncertainty in earthquake repair costs. Consequently, $C E$ is sensitive to the mean value of earthquake repair costs but not to its variance. Thus, to a real estate investor, seismic risk matters only in the mean, at least for the demonstration buildings examined here. [DOI: 10.1193/1.1810536]

\section{INTRODUCTION}

One of the most frequently occurring seismic-risk management decisions arises during the sale and resale of high-value commercial real estate in seismically active regions. A commercial building in the United States can change hands on the order of every five to ten years; the same is becoming true of foreign-owned real estate in Japan. In California and Japan, every time such a sale is made using a commercial mortgage, a study is performed to inform the lender of the building's probable maximum loss $(P M L)$. Though there is no commonly accepted quantitative definition of earthquake PML (Zadeh 2000, ASTM 1999), most working definitions involve the level of loss associated with a large, rare event such as a shaking with 0.002 mean annual exceedance frequency. Lenders refuse to underwrite a mortgage if the $P M L$ exceeds a threshold amount, usually

\footnotetext{
a) G.W. Housner Senior Researcher, California Institute of Technology, Pasadena, CA 91125

b) Professor of Applied Mechanics and Civil Engineering, Caltech, Pasadena, CA 91125

c) Doctoral candidate in Applied Mechanics, Caltech, Pasadena, CA 91125

d) Assistant Professor, Nanyang Technological University, Singapore

e) Kajima Technical Research Institute, Kajima Corporation, Tokyo, Japan

${ }^{f)}$ Kobori Research Complex, Kajima Corporation, Tokyo, Japan

g) Deputy Senior Manager, Kobori Research Complex, Kajima Corporation, Tokyo, Japan

h) Real Estate Development Division, Kajima Corporation, Tokyo, Japan

i) Architectural and Engineering Design Division, Kajima Corporation, Tokyo, Japan
} 
$20 \%$ to $30 \%$ of the property replacement cost, unless the buyer agrees to purchase earthquake insurance, out of concern that at greater levels of loss, the borrower might default on the mortgage. Thus, $P M L$ is of primary concern to lenders rather than borrowers, whose information and decision-making needs during bidding and purchase primarily involve aspects of the net asset value $(N A V)$ or return on investment $(R O I)$. For present purposes, we define $N A V$ as

$$
N A V=I(t)-L(t)
$$

where

$I(t)=$ Uncertain discounted net income stream over $t$, the lifetime of the building

$L(t)=$ Uncertain discounted future earthquake losses over the lifetime of the building

What effect does seismic risk have on $N A V$ of a real estate investment? Bear in mind that the investor's bidding decision involves other sources of risk besides seismic, such as the possibility that future market rents will be lower than expected, or that vacancy rates or operating expenses will be higher, etc. We refer to these noncatastrophe possibilities collectively as market risk. How does seismic risk compare with market risk? In other words, from the real estate investor's viewpoint, does seismic risk matter? If it does, how can investors consider both market and seismic risk in making a purchasing decision, without radically changing their business practices? Under the sponsorship of the CUREE-Kajima Joint Research Program, Phase IV, we set out to address these questions.

\section{RESEARCH OBJECTIVES}

Our research objectives were fivefold:

1. To learn directly from real estate investors how they actually make their purchasing decisions. How does the investment decision situation arise? How many and what decisions do they make before a property is purchased? On what ultimate economic values do they base these decisions? What information do they receive or collect, and how is that information generated and analyzed to estimate the value outcomes?

2. To understand how market risk is quantified in practice and to propose procedures for quantifying it for use along with seismic risk in the investment decision situation.

3. To define a procedure for calculating the probability distribution of $N A V$, including calculation of variance and higher moments of discounted future earthquake losses.

4. To formulate a decision-analysis approach to making real estate investment decisions, without requiring a costly change to current business practices.

5. To exercise and illustrate these procedures using demonstration buildings in California and Japan. When exercising the procedure, we sought to do so for two or more realistic risk-management alternatives for each building, such as buy and do nothing, purchase earthquake insurance, or perform seismic rehabilitation. 


\section{PURCHASING DECISION}

\section{INVESTOR COLLABORATION}

We arranged collaboration with two U.S. investment firms; let us refer to them as A and B. Company A is a small real estate investment group with four employees, specializing in class-A commercial properties in the range of $\$ 10$ to $\$ 100$ million value in the San Francisco Bay area. Company B is a publicly traded real estate investment trust (REIT). It specializes in developing, investing in, and managing large commercial properties in California, including office, retail, and mixed-use buildings. It owns and manages a total inventory in the range of 10 to 50 million square feet. A typical property might be 50,000 square feet to 500,000 square feet in area, class-A, low-rise, mid-rise, or high-rise. We spoke with an investment decision maker in each company, first, to assess his subjective risk attitude; second, to summarize the current practice of investment decision making; and third, to assess the reasonableness of the methodology resulting from the research. Results of these interviews are now summarized.

\section{INVESTMENT DECISION PROCESS}

Broker information package. Typically, a real estate broker approaches the investor with a package of information about an investment opportunity. The package contains a description of the property, area measures (occupied and total by type of use), information about the rent roll including income and lease term for each tenant, expected operational and capital expenses, and all other details necessary to perform a financial analysis of the property. The information is often provided in both paper and electronic format.

Preliminary assessment. The investor follows a two-stage analysis approach: in the first stage, the investor decides whether and how much to bid on the project. The analysis of the property during this stage is limited to a few labor hours. The property is screened to ensure that it is in the investor's market segment and of appropriate size and quality. The pro forma financial assumptions presented by the broker are assessed for reasonableness using in-house expertise. These assumptions include lease marketability, future vacancy, condition, and cost of management. A deterministic financial analysis is then performed to determine the yield on investment, with an analysis period of five to ten years. Limited studies are performed to determine the sensitivity of the yield to key uncertainties such as future vacancy rate and property rent inflation. The parameters of the analysis are summarized in Figure 1, based on Byrne and Cadman (1984).

This first stage lasts two to four weeks, after which the first bidding round begins. A top executive at the level of president typically decides whether and how much to bid, based on the results of these preliminary analyses. Company A's investment decision typically uses yield as the investment criterion; if the property will yield more than approximately $10 \%$, the company will bid. Within four to six weeks of the first bidding round, a winning bidder is selected. The winning bidder is not yet committed to the purchase, which is typically contingent on the results of a detailed due-diligence assessment of the property. The due-diligence stage can last 30 to 45 days. 


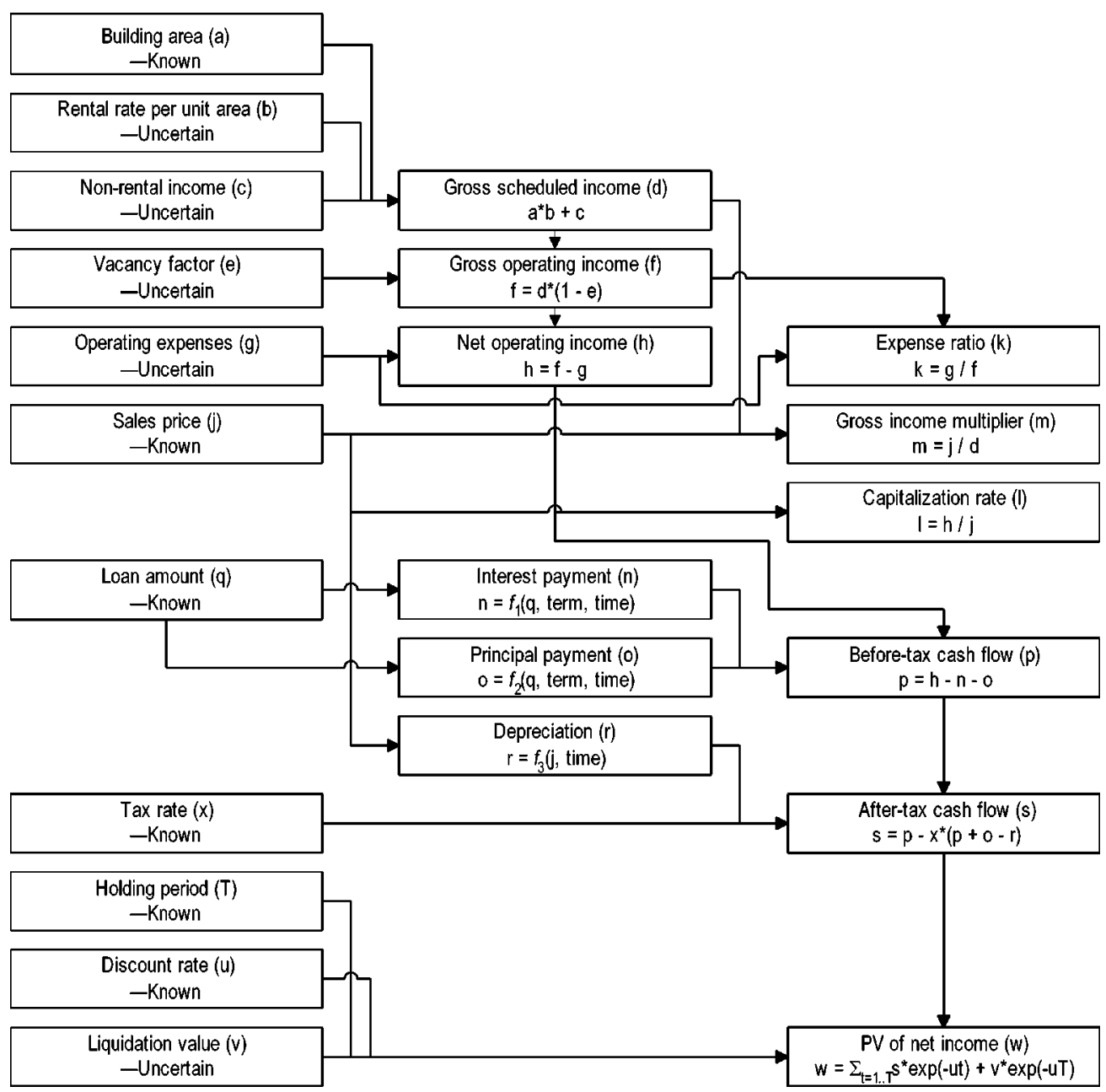

Figure 1. Calculation of the present value of an existing income property.

Due-diligence assessment, including PML. The due-diligence assessment is more extensive than the preliminary assessment. In this latter stage, attorneys confirm the leasing conditions with the current tenants, and engineers review all aspects of the property, including structural, architectural, mechanical, electrical, and plumbing components. The purpose of these engineering analyses is to determine the need for maintenance and improvement expenses. The cost of these analyses for a recent $\$ 75$ million investment by Company A was $\$ 50,000$. Company B recently spent $\$ 100,000$ on a duediligence study of a $\$ 150$ million property, and $\$ 30,000$ for a study of a $\$ 25$ million property.

For buildings valued in excess of approximately $\$ 10 \mathrm{M}$, the due-diligence assessment includes a study to evaluate earthquake risk, typically quantified as probable maximum 
loss $(P M L)$. The $P M L$ figure is used to determine whether earthquake insurance will be required. In the experience of Companies A and B, if the $P M L$ exceeds $20 \%$ to $30 \%$ of the property replacement cost, lenders require the purchase of insurance to cover the lender's equity. Annual premiums can be significant, on the order of 1 to $5 \%$ of the limit of liability, depending on property type, location, and insurance market forces. The expense can cause a borrower to pass on an otherwise attractive property. Neither Company A nor B purchases earthquake insurance to cover their own potential future earthquake losses, nor do they consider those uncertain costs in evaluating the investment yield. Thus, these investors may be exposed to significant earthquake risk, but ignore it in their financial analysis.

Seismic risk a secondary consideration. It is clear from the investor interviews that earthquake risk is a marginal consideration in their current practice, and that they consider only property damage, not business interruption or other costs. Seismic risk represents a market force only if $P M L$ exceeds a threshold amount, and earthquake insurance premiums add to the operating expense of the facility. $P M L$ is the only earthquake risk parameter the investors consider, and they do so primarily to satisfy lenders. They do not use it in their financial analysis of an investment opportunity, for three reasons:

1. Incompatible planning period. Companies A and B perform their financial analysis using a planning period of 5 to 10 years. A PML-level loss is associated with a 500-year event, which the investors consider too rare to be meaningful.

2. Incompatible with financial analysis. In standard financial practice, one typically does not consider uncertain events in the income stream.

3. Custom. Rating agencies (independent companies that review the financial status of publicly traded companies such as Company B) do not require consideration of potential earthquake losses.

Financing and purchase. If the property passes the due-diligence assessment, the investor then has 30 to 60 days to arrange the purchase financing, after which the investor is committed to the purchase and the transaction is completed. Once the property is purchased, neither Company A nor B perform any seismic risk management, other than the preparation of evacuation plans and the implementation of upgrades required by the lender. From that point until the liquidation decision, no further seismic risk management is performed.

To understand why and whether seismic risk should matter to investors, it is useful to quantify the investor's overall risk and the extent to which seismic risk contributes to it. We measure market risk and seismic risk in terms of the mean and standard deviation of present value of the net income stream (market risk) and the mean and standard deviation of present value of uncertain future earthquake repair costs (seismic risk). Seismic risk can be seen to matter if either the mean present value of uncertain future earthquake repair costs is significant compared with mean present value of the net income stream, or if the standard deviation of future earthquake repair costs is significant compared with the standard deviation of the net income stream. We first consider market risk. 


\section{QUANTIFYING MARKET RISK}

Some research has recently been performed to quantify uncertainty in market value. Holland et al. (2000) estimate the volatility of real estate return as part of a larger study of how uncertainty affects the rate of investment. Using this implied volatility of return, the authors specify a model in which property returns follow a standard Brownianmotion process with drift. By estimating the capitalization rate (i.e., return on the purchase price) for U.S. office and retail real estate investments from 1979 to 1993, they find the implied volatility of the capitalization rate for commercial real estate (i.e., the standard deviation of the difference between return in two successive years) to be on the order of 0.15 to 0.30 .

A useful measure of market risk is the coefficient of variation (COV) of property value, which is equal to the standard deviation divided by the mean value. The COV can be viewed as a multiplicative error term: a COV of 0.5 suggests that eventually realized property value might differ from the expected value at the time of purchase by a factor of $50 \%$ or more. It can be shown (see Appendix D of Beck et al. 2002) that under the Brownian-motion model of value, the $\mathrm{COV}$ of the property value is equal to several times the ratio of volatility to initial capitalization rate, i.e., if $\sigma$ represents volatility of return, $x_{0}$ represents the initial return and $r$ is the discount rate, then the COV of the present value of the net operating income stream, denoted by $\delta_{I}$, is given for very long investment periods by

$$
\delta_{I}=\frac{\sigma}{\sqrt{2 r} x_{0}}
$$

If we denote by $I$ the uncertain present value of the net income stream, and $E[I]$ denotes the expected value of the net income stream (calculated using standard financial analysis), then the variance of present value of the net income stream, denoted by $\operatorname{Var}[I]$, is given by

$$
\operatorname{Var}[I]=\left(\delta_{I} E[I]\right)^{2}
$$

For an initial capitalization rate of 0.1 , a volatility of 0.2 and a discount rate of $5 \%$, the COV of property value is in excess of 6 , a very high value! It depends, of course, on the acceptance of the Brownian-motion ("random-walk") model of capitalization rate and the empirical value for $\sigma$ estimated by Holland et al. (2000). Note that Equations 2 and 3 apply as the investment period approaches infinity, which for a discount rate of 5\% is essentially any period longer than 50 years or so. However, if one accepts that the liquidation price at the end of a shorter investment period is uncertain and will reflect the value associated with the continuing random-walk process, then one need not correct for a shorter investment period. The foregoing suggests that the effect of market risk on property value can be substantial.

This COV of value can be contrasted with the judgment of the investor from Company A, who expressed the belief that when skilled investors independently estimate the market value of an individual commercial property, they generally agree within 20 percent or so. This figure represents the investor's uncertainty on mean value and is not the 
same as the investor's uncertainty on value. It does represent a reasonable lower bound: if the investor's estimate of mean value is uncertain by $\pm 20 \%$, then his or her overall uncertainty on value must be at least $20 \%$, probably more.

Taken together, these two sources imply that market risk, as measured by the COV of long-term property value, is at least 0.2 and may exceed 1.0. A reasonable value to assume is a COV of 1.0, keeping in mind that the investor's advance knowledge of, and control over, future returns should reduce the value below the upper bound given in Equation 2.

\section{QUANTIFYING SEISMIC RISK}

Hazard and vulnerability functions. The approach used here to estimate seismic risk for a facility is to combine a probabilistic seismic hazard analysis for a facility with a probabilistic seismic vulnerability analysis. The methodology discussed here is applicable to a variety of facility types, but for present purposes we consider only buildings. The seismic hazard is represented by $G(s)$, denoting the frequency form of the site hazard function, that is, the mean annual frequency of a building experiencing shaking intensity $S \geqslant s$. The intensity measure $S$ can be expressed in any of a variety of terms, such as peak ground acceleration (PGA) or damped elastic spectral acceleration $\left(S_{a}\right)$. Herein we use the latter. The vulnerability is represented by $f_{C \mid S}(c \mid s)$, denoting the probability density of the uncertain total earthquake loss evaluated at $C=c$, given the occurrence of ground-shaking intensity $S=s$ at the site. The loss $C$ can include repair cost, loss-of-use cost, either before or after tax, to the owner, insurer, or lender, either before or after insurance or reinsurance recovery. Herein we consider only after-tax repair costs to the building owner, after any insurance recovery. It is common to normalize loss by some value $V$ such as the replacement cost of the facility. We refer to this loss as the damage factor, which we denote by $Y$, where $Y=C / V$. Thus, the probability density function of damage factor $Y$ given $S=s$ and that of the loss are related by

$$
f_{Y \mid S}(y \mid s)=f_{C \mid S}(y V \mid s)
$$

Figure 2 depicts generic seismic hazard and (normalized) vulnerability functions. The seismic hazard function $G(s)$ is derived by considering the seismic environmentthe nearby faults, their seismicity, seismic attenuation, and site soil conditions. The seismic vulnerability function can be developed by a variety of means. Here we use the assembly-based vulnerability (ABV) method, described in Porter et al. (2001, 2002). In the present study we enhanced the method by including a stochastic structural model, with uncertain mass, damping, and force-deformation behavior, along with uncertain ground motion, assembly capacity, unit repair costs, and contractor overhead and profit. We also developed some new assembly fragility functions and cost distributions; these are discussed later.

Intensity probability distribution and marginal distribution of cost given earthquake. Let $s_{0}$ denote a threshold level of shaking that causes nonzero damage. Let $f_{S \mid S>s_{0}}(s)$ denote the probability density of shaking intensity s, given that $S>s_{0}$. It is given by 

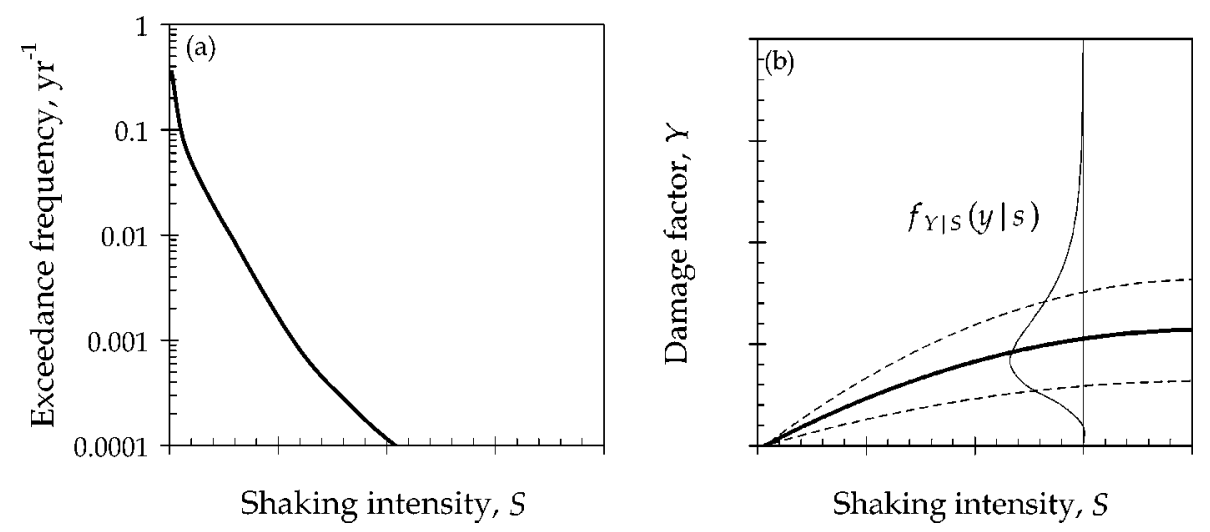

Figure 2. (a) Generic seismic hazard function, and (b) seismic vulnerability function.

$$
f_{S \mid S>s_{0}}(s)=\frac{\left|G^{\prime}(s)\right|}{G\left(s_{0}\right)}
$$

where $G^{\prime}(s)$ is the first derivative of the hazard function evaluated at $s$. From the theorem of total probability, the probability density function for the earthquake loss given a damaging earthquake is

$$
f_{C \mid S>s_{0}}(c)=\int_{s_{0}}^{\infty} f_{C \mid S}(c \mid s) f_{S \mid S>s_{0}}(s) d s
$$

If the temporal occurrence of shaking at the site with intensity $S>S_{0}$ is modeled by a Poisson process with the mean rate of occurrence denoted by $G\left(s_{0}\right)$, and it is assumed that, if damaged, the building is restored to its pre-earthquake state, then the $n$th moment of cost given a damaging earthquake is given by

$$
\begin{aligned}
E\left[C^{n} \mid S>s_{0}\right] & =\int_{0}^{\infty} c^{n} f_{C \mid S>s_{0}}(c) d c \\
& =\int_{c=0}^{\infty} \int_{s=s_{0}}^{\infty} c^{n} f_{C \mid S}(c \mid s) f_{S \mid S>s_{0}}(s) d s d c \\
& =\int_{s=s_{0}}^{\infty} E\left[C^{n} \mid S=s\right] f_{S \mid S>s_{0}}(s) d s
\end{aligned}
$$

where $E\left[C^{n} \mid S=s\right]$ is the $n$th moment of $C$ given intensity $s$, given by

$$
E\left[C^{n} \mid S=s\right]=\int_{c=0}^{\infty} c^{n} f_{C \mid S}(c \mid s) d c
$$


Moments of cost during time period $t$. Using these results, one can calculate the mean loss over time period $t$, denoted by $\bar{C}(t)$, in terms of the mean loss given that a damaging earthquake has occurred:

$$
\begin{aligned}
\bar{C}(t) & =G\left(s_{0}\right) t E\left[C \mid S>s_{0}\right] \\
& =\int_{s=s_{0}}^{\infty} G\left(s_{0}\right) t E[C \mid S=s] f_{S \mid S>s_{0}}(s) d s \\
& =t \int_{s_{0}}^{\infty} E[C \mid S=s]\left|G^{\prime}(s)\right| d s
\end{aligned}
$$

where Equations 4 and 6 have been used, and $E[C \mid S=s]$ can be calculated using Equation 7. The expected annual loss (denoted here by $E A L$ ) would be given by $\bar{C}(t=1 \mathrm{yr}$ ). Similarly, the mean-square loss over time period $t$ is given by

$$
\overline{C^{2}}(t)=G\left(s_{0}\right) t E\left[C^{2} \mid S>s_{0}\right]=t \int_{s=s_{0}}^{\infty} E\left[C^{2} \mid S=s\right]\left|G^{\prime}(s)\right| d s
$$

Present value of repair costs. It is necessary for this study to investigate the present value of the uncertain future losses (i.e., discounted future losses) over some time period $t$, such as the designated lifetime of the building. The uncertainties in the earthquake occurrences, that is, the number of earthquakes $N(t)$ and the arrival times $T_{1}, T_{2}, \ldots$, as well as the uncertainties in the earthquake losses $C_{1}, C_{2}, \ldots$, render the total earthquake loss $L(t)$ uncertain. If a probability model is specified for the temporal occurrence of earthquakes affecting the building site and the probability model in Equation 5 for $f_{C \mid S>s_{0}}(c)$ is used to describe the uncertain loss $C_{k}$ caused by an earthquake at time $T_{k}$, there is an implied probability distribution for $L(t)$. It is not an easy task, however, to determine this probability density function.

We investigate statistical properties of $L(t)$, considering only Poisson events and conditioned on the Poisson rate of events with intensity greater than a threshold value, $S$ $>s_{0}$. To study the statistical properties of the total earthquake loss $L(t)$, several simplifying assumptions that are often made are adopted here:

1. The number of earthquake events of interest during the lifetime $t, N(t)$, is modeled by a Poisson process with mean occurrence rate $G\left(s_{0}\right)$.

2. The earthquake losses $\left\{C_{1}, C_{2}, \ldots\right\}$ are assumed to be independent and identically distributed (i.i.d.) with probability density function $f_{C \mid S>s_{0}}(c)$ given by Equation 5.

3. These losses are also assumed to be independent of the time of occurrence of the earthquakes, that is, the arrival times $\left\{T_{1}, T_{2}, \ldots\right\}$.

These assumptions would be reasonable, for example, if the seismic hazard were stationary (time-independent) and the building were always restored to its original state before the next damaging event so that the building vulnerability $f_{C \mid S}(c \mid s)$ remained the same. 
In the past, expressions that are of a computationally manageable form have only been obtained for the first moment (i.e., mean) of $L(t)$. By directly conditioning on the number of earthquakes occurring during the lifetime $t$, Ang et al. (1996) adopted an expression for the expected value of $L(t)$ that involves a double sum over all possible number of earthquakes during the lifetime. Kiremidjian (1998) presents expressions for the first and second moments of $L(t)$ conditioned on knowledge of the number of characteristic and Poisson events affecting the property in time $t$. In Appendix F of Beck et al. (2002), we develop an approach to obtain the statistical properties of $L(t)$ that leads to the following expression for the logarithm of its moment-generating function:

$$
\ln M_{L(t)}(x)=\frac{G\left(s_{0}\right)}{r} \sum_{n=1}^{\infty} \frac{x^{n}}{n ! n} E\left[C^{n}\right]\left(1-e^{-n r t}\right)
$$

The mean and variance of $L(t)$ can be readily derived from the first and second derivatives of Equation 10 with respect to $x$ when evaluated at $x=0$ (these correspond to the first and second cumulants - see Papoulis 1991). This leads directly to Equations 11 and 12 for the mean and variance of the present value of lifetime earthquake loss:

$$
\begin{gathered}
E[L(t)]=\frac{E A L}{r}\left(1-e^{-r t}\right) \\
\operatorname{Var}[L(t)]=\frac{G\left(s_{0}\right)}{2 r} E\left[C^{2}\right]\left(1-e^{-2 r t}\right)
\end{gathered}
$$

Note that $\operatorname{Var}[L(t)]$ depends on $E\left[C^{2}\right]$ rather than on $\operatorname{Var}[C]$. This means that even in the case when $C_{k}$ are fixed to a common value $\left(\operatorname{Var}\left[C_{k}\right]=0\right)$, there will still be variability in $L(t)$, because of the variability in the arrival times of the events. With these expressions for seismic risk, we are now in a position to show how market and seismic risk combine to affect the value of a property to a real estate investor.

\section{PROBABILITY DISTRIBUTION OF NET ASSET VALUE}

The basic measure of value for the purchase (or construction) of income-producing property that is used in this study is its lifetime net asset value:

$$
V\left(t_{L}\right)=I\left(t_{L}\right)-C_{o}-L\left(t_{L}\right)
$$

where

$I\left(t_{L}\right)=$ Present value of net income stream over the property lifetime $t_{L}$, ignoring earthquakes

$C_{0}=$ Initial investment, i.e., property equity

$L\left(t_{L}\right)=$ Present value of losses from future earthquakes over lifetime $t_{L}$

Only $C_{0}$ is known with certainty. The uncertainty in the value of $I\left(t_{L}\right)$ creates a market risk while the uncertainty in $L\left(t_{L}\right)$ creates seismic risk. The resulting uncertainty in net asset value $V$ can be described by a risk-return profile: 


$$
P(v)=\operatorname{Prob}[V>v \mid \text { Seismic \& market risks }]
$$

based on the probability models for $I\left(t_{L}\right)$ and $L\left(t_{L}\right)$. Thus, for a specified property, $P(v)$ gives the probability that the lifetime net asset value $V$ exceeds a value $v$.

It is not an easy task to derive $P(v)$ from the models for the seismic and market risk, although the mean and variance of $V$ are readily derived:

$$
\begin{gathered}
E\left[V\left(t_{L}\right)\right]=E\left[I\left(t_{L}\right)\right]-C_{o}-E\left[L\left(t_{L}\right)\right] \\
\operatorname{Var}\left[V\left(t_{L}\right)\right]=\operatorname{Var}\left[I\left(t_{L}\right)\right]+\operatorname{Var}\left[L\left(t_{L}\right)\right]
\end{gathered}
$$

where $C_{0}$ is the purchase price $P$ plus any up-front retrofit costs and $E\left[L\left(t_{L}\right)\right]$ and $\operatorname{Var}\left[L\left(t_{L}\right)\right]$ are given by Equations 11 and 12, respectively. Equation 15 is based on stochastic independence of $I\left(t_{L}\right)$ and $L\left(t_{L}\right)$. The mean and variance of $I\left(t_{L}\right)$ depend on the probability model for the market risk, that is, the variability in the net income stream over the lifetime $t_{L}$.

A stochastic-process model for the net income stream is developed in Appendix E of Beck et al. (2002). It is based on modeling the after-tax income per period as a Wiener process (Papoulis 1991), which is a continuous-time version of a random-walk model. In this model, the after-tax income per period at time $t$ is a Gaussian stochastic process with mean $E\left[r_{e}(t)\right] P$, variance $\left(\operatorname{Var}\left[r_{e}(0)\right]+\lambda^{2} t\right) P^{2}$, and autocovariance $\left(\operatorname{Var}\left[r_{e}(0)\right]\right.$ $\left.+\lambda^{2} \min (t, \tau)\right) P^{2}$ at times $t$ and $\tau$. Here, $r_{e}(t)$ is the after-tax yield at time $t, \lambda^{2}$ is the volatility (the rate of increase per unit time in the variance of the after-tax yield), and $P$ is the purchase price for the property. For fixed-interest-rate loans and a constant tax rate, the uncertainty in the after-tax yield is dominated by the uncertainty in the capitalization rate, that is, the ratio of the net operating income per period to the purchase price. In turn, the uncertainty in the capitalization rate depends primarily on the unknown variations in future rental rates, vacancy rates, and operating expenses. The effect of these uncertainties is captured in the stochastic model for $r_{e}(t)$ by the linearly increasing variance, $\operatorname{Var}\left[r_{e}(t)\right]=\operatorname{Var}\left[r_{e}(0)\right]+\lambda^{2} t$. It turns out that this stochastic model for $r_{e}(t)$ implies that $I\left(t_{L}\right)$, the discounted after-tax net income stream over the lifetime $t_{L}$, has a Gaussian distribution with mean and variance

$$
\begin{gathered}
E\left[I\left(t_{L}\right)\right]=P \int_{0}^{t_{L}} e^{-r t} E\left[r_{e}(t)\right] d t \\
\operatorname{Var}\left[I\left(t_{L}\right)\right]=\frac{\lambda^{2} P^{2}}{2 r^{3}}\left[1-4 e^{-r t_{L}}+3 e^{-2 r t_{L}}+2 r t_{L} e^{-2 r t_{L}}\right]+\operatorname{Var}\left[r_{e}(0)\right] \frac{P^{2}}{r^{2}}\left[1-e^{-r t_{L}}\right]^{2}
\end{gathered}
$$

If the mean after-tax yield $E\left[r_{e}(t)\right]$ is taken as constant and $\operatorname{Var}\left[r_{e}(0)\right]=0$, then as $t_{L}$ $\rightarrow \infty$ :

$$
E\left[I\left(t_{L}\right)\right] \rightarrow \frac{P}{r} E\left[r_{e}(1)\right]
$$




$$
\operatorname{Var}\left[I\left(t_{L}\right)\right] \rightarrow \frac{P^{2}}{2 r^{3}} \operatorname{Var}\left[r_{e}(1)\right]
$$

This implies that as $t_{L} \rightarrow \infty$, the coefficient of variation on $I\left(t_{L}\right)$ is given by

$$
\delta_{I}=\frac{1}{\sqrt{2 r}} \delta_{r_{e}}
$$

where $\delta_{r_{e}}$ is the coefficient of variation in the after-tax yield over one period. Equation 20 is the continuous-time analog of the discrete-time result given in Equation 2.

Although $I\left(t_{L}\right)$ has a Gaussian distribution, this is not true for the discounted lifetime earthquake losses $L\left(t_{L}\right)$ under the seismic risk model described above. Therefore, the net asset value $V\left(t_{L}\right)$ in Equation 13 does not have a Gaussian distribution. In principle, the probability distribution for $V$ is determined (through an inverse-Laplace transform) by its moment-generating function. Although this inversion is not an easy task, the momentgenerating function for $V$ is readily derived:

$$
\ln M_{V\left(t_{L}\right)}(\xi)=\ln M_{I\left(t_{L}\right)}(\xi)-C_{o}+\ln M_{L\left(t_{L}\right)}(-\xi)
$$

where $\ln M_{L\left(t_{L}\right)}(-\xi)$ is given by Equation 10, and

$$
\ln M_{I\left(t_{L}\right)}(\xi)=E\left[I\left(t_{L}\right)\right] \xi+\frac{1}{2} \operatorname{Var}\left[I\left(t_{L}\right)\right] \xi^{2}
$$

because $I\left(t_{L}\right)$ has Gaussian distribution. Equation 21 is all that is needed either for riskneutral or for risk-averse decision making (for the utility function that is discussed next).

\section{DECISION-ANALYSIS APPROACH TO INVESTMENT DECISION MAKING}

Decision analysis is an outgrowth of game theory; the interested reader is referred to Von Neumann and Morgenstern (1944) or Howard and Matheson (1989) for an overview. We and other authors have written about using decision analysis for seismic risk management (Porter 2000) and for real estate investment decision making (Ratcliff and Schwab 1970, Byrne and Cadman 1984). It is a modest step to combine the two, to account for seismic risk, market risk, and the decision maker's risk attitude in real estate investment decisions. In this discussion, we consider a real estate investment decision to have three elements: a set of alternatives or choices (e.g., do not buy, buy and leave as-is, buy and retrofit, buy and purchase insurance); one or more value outcomes of interest (e.g., net asset value); and uncertainties such as future vacancy rate or future market rent that may depend on the selected alternative and are relevant to the value outcome. Furthermore, a decision maker has a subjective time preference for money-quantified here by risk-free after-inflation discount rate - and a subjective risk attitude, which is quantified with a utility function, $u(x)$, where $x$ is the value outcome such as the decision maker's total wealth.

A utility function relates the value outcome to an abstract quantity called utility that measures the subjective desirability of outcome $x$. In the present study, we consider only 
monetary value as the argument of the utility function, and ignore entertainment value. The fundamental distinction between decision making under engineering-economics principles and under decision analysis springs from the utility function: instead of selecting the alternative that maximizes return or mean net asset value, one selects the alternative that produces the maximum expected value of utility. For a monotonically increasing utility function (typical), it is equally valid to select the alternative that maximizes the inverse of the expected value of the utility function, referred to as the certainty equivalent, denoted by $C E$ :

$$
C E=u^{-1}(E[u(x)])
$$

where

$$
E[u(x)]=\int_{-\infty}^{\infty} u(x) f_{X}(x) d x
$$

and where $X$ denotes the uncertain value outcome of a deal and $f_{X}(x)$ denotes its probability density function. Note that $C E$ has units of money here, and can be seen as the amount of money one should take for certain in exchange for an uncertain deal- the price that makes one just indifferent between buying and not buying a lottery ticket, for example.

For the typical decision maker dealing with monetary value outcomes, the utility function can reflect the fact that a decision maker can find more or less desirability in incremental gains or losses of wealth, depending on the total gain or loss. That is, the pain of losing an amount $x$ might be far greater than the pleasure of gaining $x$. This is risk aversion, and can be important when dealing with large stakes. Depending on the stakes, decision makers might be risk-averse, risk-neutral (valuing gains and losses equally), or risk-seeking (valuing gains more than equivalent losses). In the present study, we assume risk-averse decision making with utility functions of the form

$$
u(x)=1-\exp (-x / \rho)
$$

where $u$ represents utility of the term in parentheses, $x$ represents monetary value, and $\rho$ is the risk tolerance parameter, in units of money. A utility function of the form of Equation 25 has three desirable features: (1) one can make decisions based on the change of wealth, rather than on total wealth - and thus ignore other deals that might affect wealth; (2) this form passes through the origin, so negative value has negative utility, positive value has positive utility; and (3) the decision maker's risk attitude is completely defined with a single parameter, $\rho$.

In Porter (2000), an interview process is described to elicit a particular decision maker's $\rho$, and the process is exercised to elicit $\rho$ for five decision makers using a series of 20 to 40 hypothetical deals. In Beck et al. (2002), we present a script in English and Japanese to implement this interview process, along with results for several additional U.S. and Japanese decision makers. 

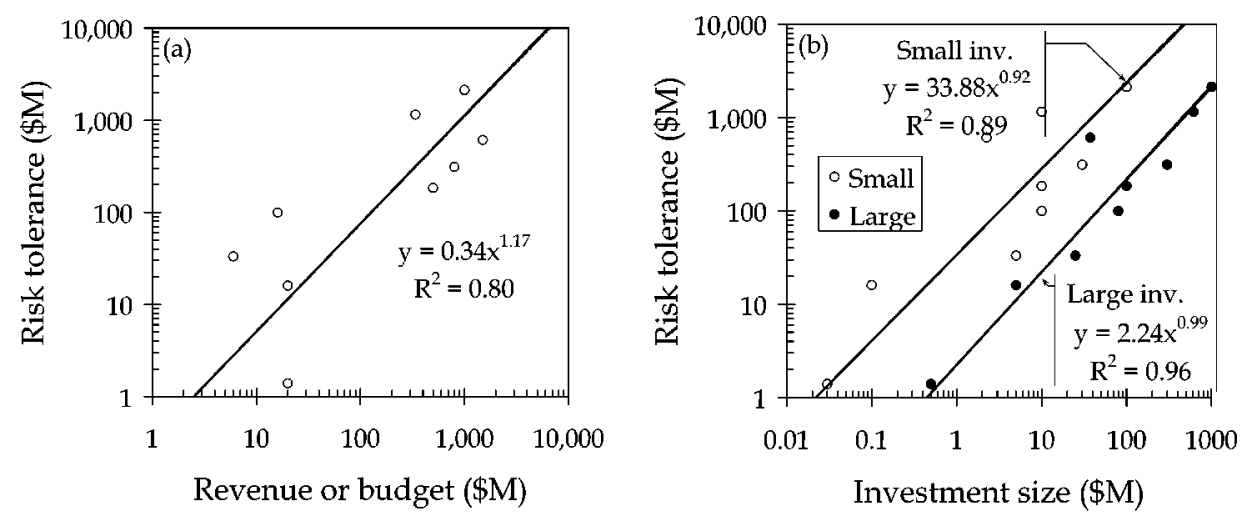

Figure 3. Relationship of implied risk tolerance $\rho$ to (a) annual revenue or budget, and (b) size of investments with which the decision maker typically deals.

In both studies, the value of $\rho$ is found to be correlated with the decision maker's annual revenue or budget, or with the size of the largest deal in which he or she typically invests, through a power function

$$
\rho \approx a y^{b}
$$

in which $a$ and $b$ are constants, and $y$ represents either revenue or the up-front cost of a large investment. These trends are shown in Figure 3.

In Beck et al. (2002), we show using Equations 10, 21, 22, 24, and 25 that the certainty equivalent of a real estate investment decision with seismic risk is given by

$$
C E=E[I(t)]-C_{0}-E[L(t)]-\frac{\operatorname{Var}[I(t)]+\operatorname{Var}[L(t)]}{2 \rho}-R
$$

where $I(t), C_{0}, L(t)$, and $\rho$ are as defined above, and $R$ is a remainder term associated with higher moments of income and earthquake loss, and is shown to be small. If $\operatorname{Var}[L(t)] \ll \operatorname{Var}[I(t)]$, as our analyses suggest, then Equation 27 simplifies to

$$
C E \approx E[I(t)]-C_{0}-E[L(t)]-\frac{\left(\delta_{I} E[I(t)]\right)^{2}}{2 \rho}
$$

which is simply the expected $N A V$ less a term to account for market risk $\delta_{I}$ and risk tolerance $\rho$. Risk tolerance can be assessed for the investment firm to ensure a consistent approach to risk. In the absence of better information, market risk and $\delta_{I}$ can be estimated as discussed above (on the order of 0.2 to 1.0 ) or by the investor's judgment.

\section{U.S. DEMONSTRATION BUILDING}

To illustrate the calculation of $N A V$, we selected three demonstration buildings: one in the United States and two in Japan. The U.S. demonstration building is a real, sevenstory, 66,000 -square-foot $\left(6,200 \mathrm{~m}^{2}\right)$ hotel located in Van Nuys, CA, at $34.221^{\circ} \mathrm{N}$, 


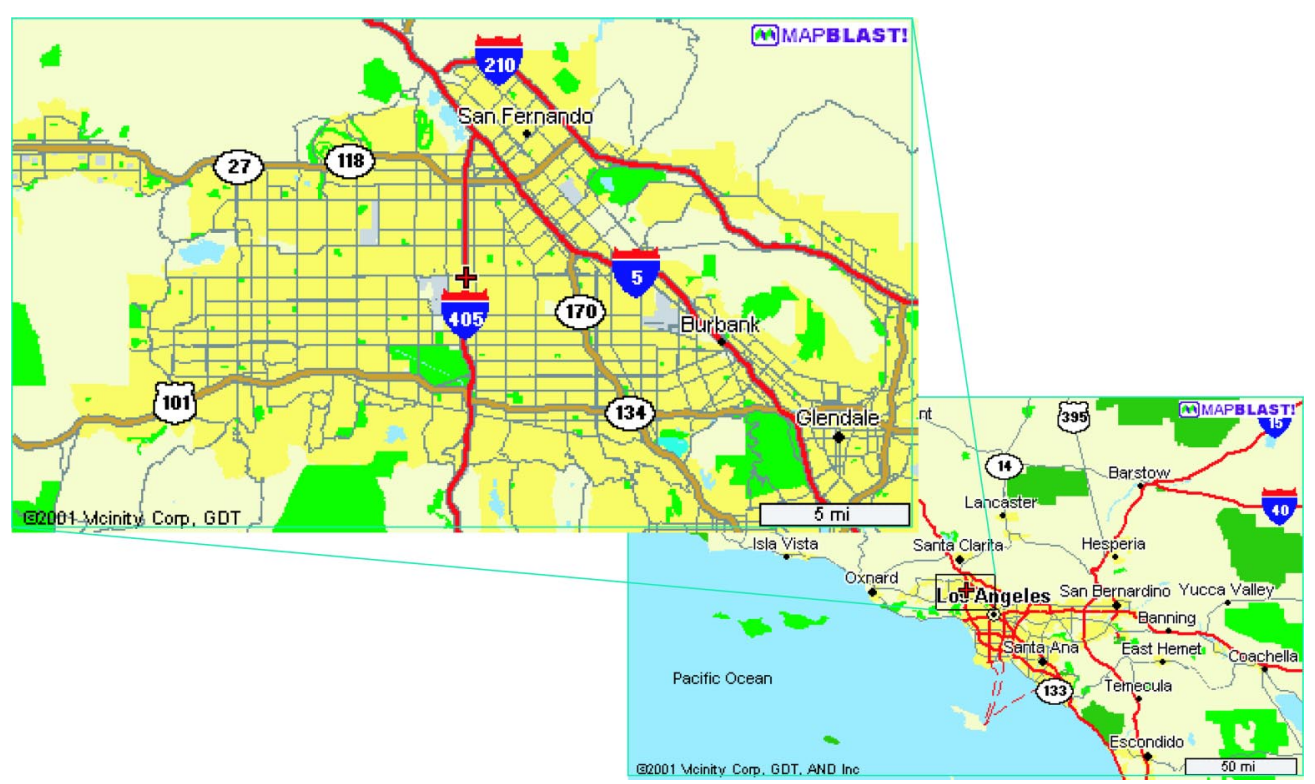

Figure 4. Location of CUREE demonstration building, at the "+" symbol near "405."

$118.471^{\circ} \mathrm{W}$, in the San Fernando Valley of Los Angeles County. The location is shown in Figure 4. It was built in 1966 according to the 1964 Los Angeles City Building Code. The lateral force-resisting system is a perimeter nonductile reinforced-concrete moment frame in both directions. The building was lightly damaged by the M6.6 1971 San Fernando event, approximately $20 \mathrm{~km}$ to the northeast, and severely damaged by the M6.7 1994 Northridge earthquake, whose epicenter was approximately $4.5 \mathrm{~km}$ to the southwest. The building has been studied extensively, e.g., by Jennings (1971), Scholl et al. (1982), Islam (1996a, 1996b), Islam et al. (1998), and Li and Jirsa (1998). Trifunac et al. (1999) provide a detailed account of the physical damage to the structure in the 1994 Northridge earthquake. This building is also the subject of current study developing a second-generation performance-based earthquake engineering (PBEE-2) methodology by the Pacific Earthquake Engineering Research Center (Porter 2003). We examine the building as it existed just prior to the 1994 Northridge Earthquake, not as it exists today. The building was repaired and seismically strengthened after 1994.

Soil conditions at the site are found in Tinsley and Fumal (1985), who mapped surficial soil deposits in the Los Angeles region using a variety of sources. Based on the shear-wave velocity, the site corresponds to Site Class D (stiff soil), as defined by the International Code Council (2000). In his study of the same building, Islam (1996b) reached the same conclusion. The site hazard is calculated using Frankel and Leyendecker's (2001) software for 5\%-damped spectral acceleration at 0.75 -sec and 1.5-sec periods, and adjusted to Site Class D shaking using factors taken from the 2000 International Building Code (ICC 2000). The resulting hazard function is shown in Figure 5a. 

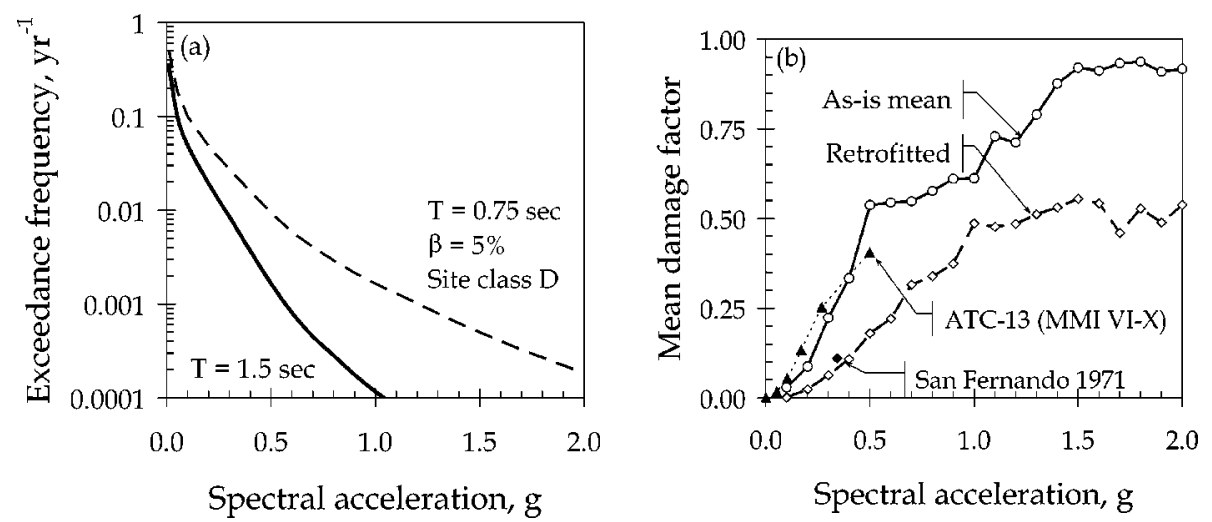

Figure 5. (a) Site hazard, and (b) seismic vulnerability for CUREE demonstration building.

We used the assembly-based vulnerability (ABV) methodology to estimate the probabilistic seismic vulnerability function of the building as it existed just prior to the 1994 Northridge earthquake (the as-is case, with $T \approx 1.5 \mathrm{sec}$ ), as well as under a hypothetical seismic retrofit involving the addition of reinforced-concrete shear walls at the perimeter moment frames $(T \approx 0.75 \mathrm{sec})$. The $A B V$ methodology is described in detail elsewhere (e.g., Porter et al. 2001, 2002). In summary, it is a simulation technique to probe structural response, detailed physical damage at the level of individual components, system-performance level, repair cost, and repair duration. It accounts for uncertainty in ground motion, mass, damping, force-deformation behavior, component damageability, and repair costs. In the present study, we added stochastic structural modeling to the ABV methodology and refined the loss model to treat contractor overhead and profit separately from direct costs. We also developed new assembly fragility functions and cost distributions. We used ABV because it allows one to avoid many of the simplifying assumptions and recourse to expert opinion required by other methods that use pushover-type analyses, and it carefully propagates all important sources of uncertainty. The interested reader is referred to Beck et al. (2002) for details of the seismic vulnerability analyses of the demonstration building.

The ABV analyses produced the seismic vulnerability functions shown in Figure $5 \mathrm{~b}$. The $x$-axis represents 5\%-damped elastic spectral acceleration (which we denote by $S_{a}$ ) at the building's small-amplitude fundamental period of $1.5 \mathrm{sec}$. The $y$-axis measures repair cost as a fraction of replacement cost. Each circle represents the average of 20 loss simulations. Each simulation included one nonlinear time-history structural analysis using one ground-motion time history, one simulation of the (uncertain) mass, damping, and force-deformation characteristics of the building, one simulation of the damageability of each of 1,233 structural and nonstructural components, and one simulation of the unit-repair cost for each of 17 combinations of component type and damage state.

The analysis includes 20 simulations for each of $20 S_{a}$ increments from $0.1 \mathrm{~g}$ to 2.0 g. The 400 nonlinear time-history structural analyses took approximately 12 hours of computer time on an ordinary desktop computer; the subsequent damage and loss analy- 
Table 1. Peak drift ratios recorded in Northridge 1994 and estimated for $S_{a}=0.5 \mathrm{~g}$

\begin{tabular}{lcc}
\hline \hline Level & Recorded & $\begin{array}{c}\text { Estimated } \\
\text { mean } \pm \text { stdev }\end{array}$ \\
\hline 2nd story & $1.8 \%$ & $3.4 \% \pm 1.8 \%$ \\
1 st story & $1.1 \%$ & $2.6 \% \pm 1.2 \%$ \\
\hline \hline
\end{tabular}

sis took an hour. (Setup, however, took many days for each model, i.e., for the as-is and for the retrofitted version of the building.). For reference, Figure $5 \mathrm{~b}$ also shows the ATC-13 mean seismic vulnerability function for a high-rise reinforced-concrete nonductile moment-frame building, and the loss to this building caused by the 1971 San Fernando earthquake.

Structural response and damage to U.S. demonstration building. In addition to economic loss, the ABV analysis produces statistics of structural response (engineering demand parameters or $E D P$ ) and physical damage (damage measures or $D M$ ) as intermediate results. Economic loss is unavailable for the 1994 Northridge earthquake $\left(S_{a}\right.$ $=0.5 \mathrm{~g}$ ), but response and damage statistics are available. Table 1 presents peak transient drift ratios recorded in the 1994 Northridge earthquake and those estimated here for $S_{a}=0.5 \mathrm{~g}$. Only the first-and second-story drift ratios in Northridge are available because of the location of the instruments in the building. (Recorded values taken from Li and Jirsa [1998].) Agreement is only fair, with recorded displacements in Northridge falling 0.9 to 1.25 standard deviations below the estimated mean for a similar sized event, i.e., near the 10th to 20th percentiles of the suite of simulations.

Some meaningful summary statistics of physical damage can be presented. Figure 6 shows the average fraction of beams and columns damage as a function of spectral acceleration. (The study also examined a variety of nonstructural elements, but for brevity
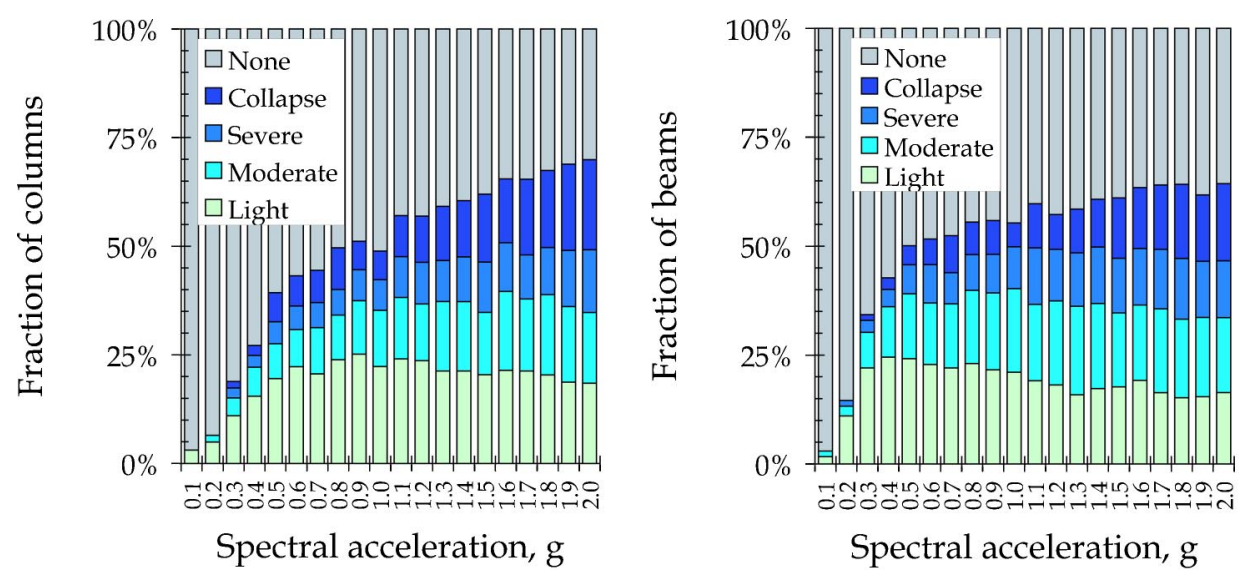

Figure 6. Assembly damage under as-is conditions. 


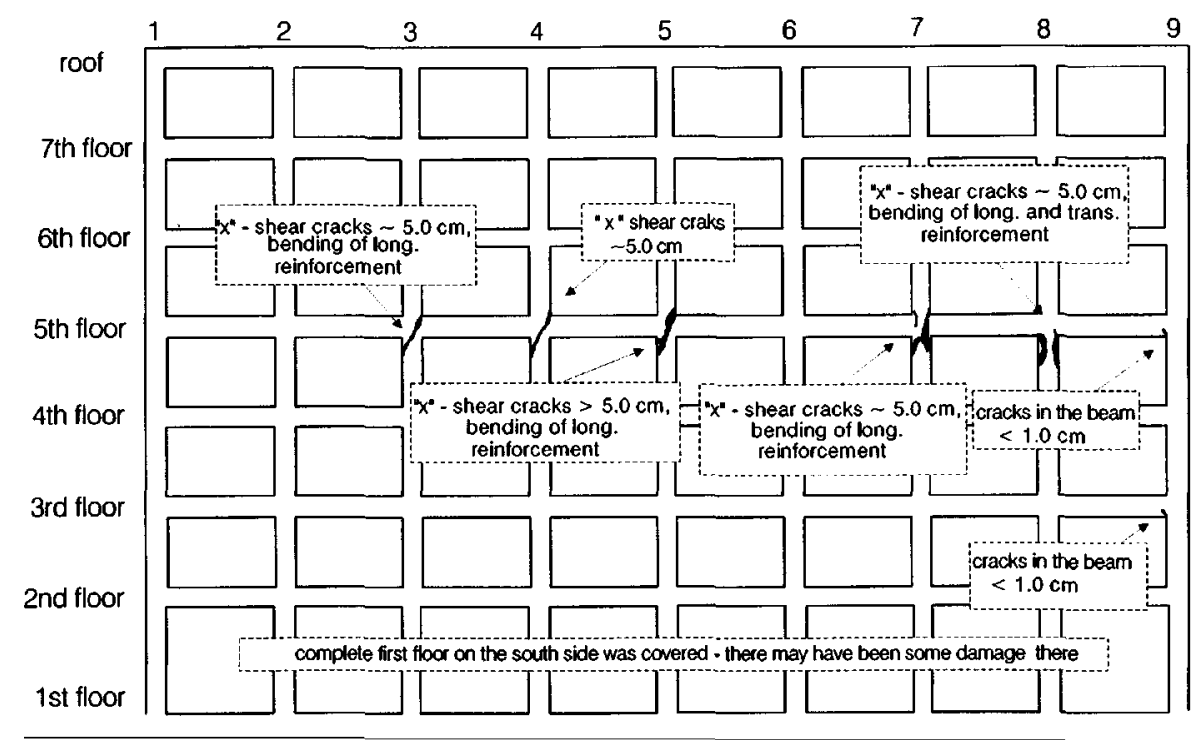

Figure 7. Structural damage in 1994 Northridge earthquake, south frame (Trifunac et al. 1999).

we do not present those results here; the interested reader is referred to Beck et al. 2002.) Trifunac et al. (1999) present detailed information from the 1994 Northridge earthquake $\left(S_{a}=0.5 \mathrm{~g}\right)$ about beam and column damage to the south frame at the second floor and above; see Figure 7. Agreement for columns is good: 5 of 54 observable columns above the first floor had shear failure, representing $9 \%$ in the "collapsed" damage state; simulation approximately matches observation, with 4.5 columns on average in the collapsed damage state. Agreement for beams is poor: we estimated on average $40 \%$ of beams damaged at $S_{a}=0.50 \mathrm{~g}$; few actually were. We infer that the beam-columns in the real building are either less fragile or experienced lower seismic demand than modeled here.

Statistical distributions of response and loss. We performed 400 simulations that included structural response, damage, and loss, so meaningful data are available about how well idealized statistical distributions fit the simulations. (Bear in mind that, while we imposed idealized distributions on mass, damping, force-deformation characteristics, unit assembly capacity, and unit repair costs, we did not impose any distributions on ground-motion characteristics, structural response, or total cost.) We found that peak relative floor displacement, peak transient drift ratio, and total repair cost can be adequately modeled as lognormally distributed, passing Kolmogorov-Smirnov goodnessof-fit tests at the 5\% significance level, as shown in Figure 8.

Dominance of moderate shaking in economic risk. If one evaluates Equation 8 for $t=1 \mathrm{yr}$ and plots the integral with an upper bound of integration at increasing levels of $S_{a}$, one can see the relative contribution of various intensity levels to the expected annualized loss, as shown in Figures 9a and 9b. The former shows the cumulative $E A L$ as a function of $S_{a}$; the latter, as a function of the mean return period. The figure suggests 

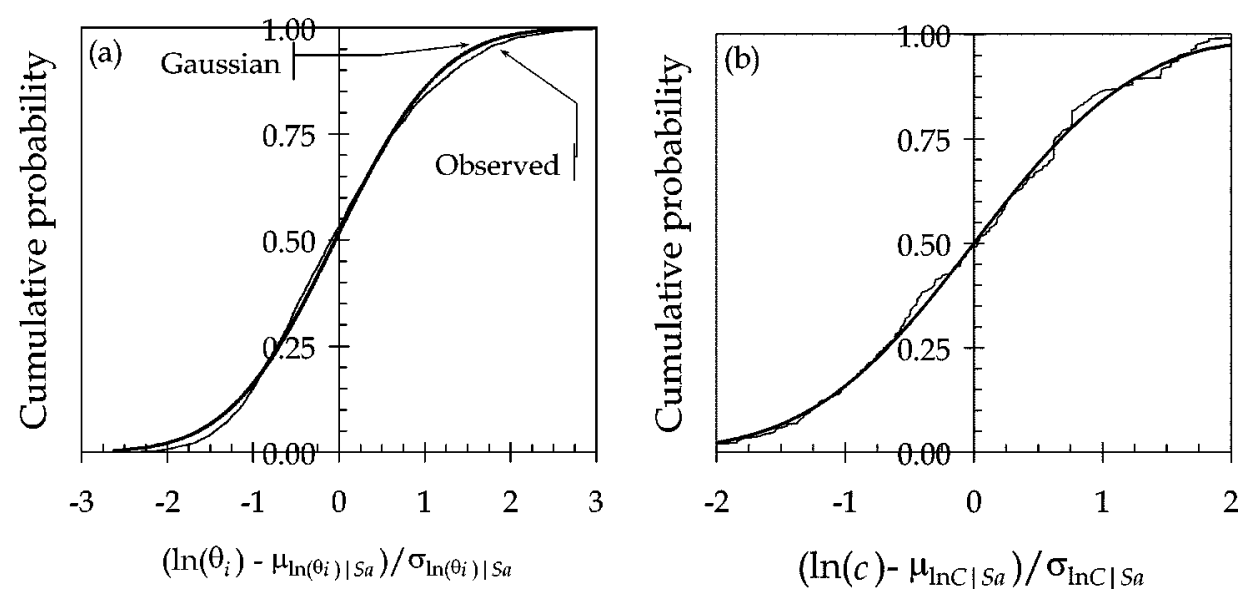

Figure 8. (a) Distribution of peak drift ratio given $S_{a}$, and (b) repair cost given $S_{a}$.

three things: that (1) in the case of the as-is demonstration building, relatively frequent events dominate economic risk; (2) a 500-year event (a $P M L$-level loss) is a poor indicator of economic risk; and (3) seismic risk is dominated by shaking levels where linear structural analysis might yield realistic results. Some implications are discussed in a companion paper by Porter et al. (2004, in this issue), the most notable of which is that it may be possible to use a single linear structural analysis and a linear version of $A B V$ to estimate both expected annualized loss $(E A L)$ and a more useful metric of economic performance called probable frequent loss $(P F L)$. $P F L$ is defined as the mean loss conditioned on the occurrence of shaking with $10 \%$ exceedance probability in 5 years. As shown in the companion paper, EAL can be estimated as the product of $P F L$ and a site economic hazard coefficient, $H$, that can be provided on paper maps or via a simple computerized database application and disseminated over the Internet.
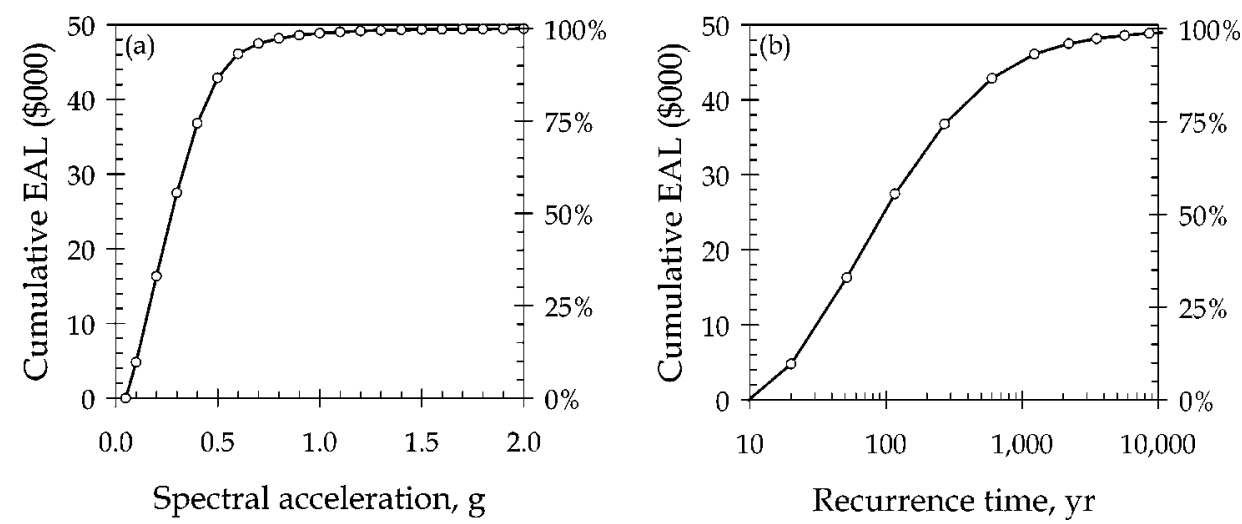

Figure 9. Cumulative contribution to expected annualized loss. 


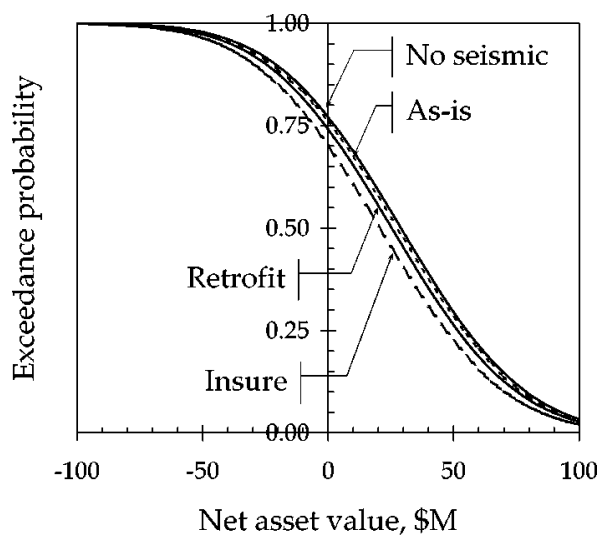

Figure 10. Net asset value of U.S. demonstration building.

Net asset value. Evaluation of Equations 14 and 15 produces the probability distributions of $N A V$ shown in Figure 10. The figure shows four exceedance curves of $N A V$ : without seismic risk, as-is, with the hypothetical retrofit, and assuming the purchase of insurance. Here, insurance is assumed to cost $3.6 \%$ of the value of the property per year (a reasonable rate on line for this type of property) and a deductible of $\$ 250,000$. The plot yields three observations: (1) seismic risk only modestly decreases mean $N A V$ (there is a modest shift to lower value when one accounts for seismic risk); (2) uncertainty in earthquake loss is negligible compared with uncertainty in income (the width of the four curves are about the same); and (3) it is a little difficult to see how one would make an investment decision using these curves. A decision-analysis tool that employs the scalar metrics of $C E$ might be more valuable.

Certainty equivalent. This is a $\$ 10 \mathrm{M}$ investment; from Figure $2 \mathrm{~b}$, it can be inferred that a decision maker investing in the property would have a risk tolerance of $\$ 20 \mathrm{M}$ to $\$ 500 \mathrm{M}$. (Risk tolerance here refers to $\rho$, the parameter of the utility function, and does not imply that the investor is willing to lose some fixed amount of money.) Using $\rho$ $=\$ 100 \mathrm{M}$, a risk-free after-inflation discount rate of $2 \%$, and uncertainty on income $\delta_{I}$ $=1.0$, the decision analysis yields the certainty equivalents shown in Table 2 . Note that the $C E$ for the do-not-buy alternative is zero. The table shows the imaginary case of no seismic risk, for reference. These results illustrate four important points.

1. Decision analysis yields a clear distinction between the three alternatives and shows that seismic risk makes a difference in the $C E$ of the investment opportunity.

2. Decision analysis helps to make sense of uncertain $N A V$, yielding a scalar $C E$ value that accounts for uncertainty and for the decision maker's risk attitude.

3. The uncertainty on earthquake loss can be ignored. It is small compared with market risk, emphasizing the irrelevance of $P M L$ to the investor.

4. The expected value of earthquake loss is significant compared with income. 
Table 2. Certainty equivalent of U.S. investment alternatives

\begin{tabular}{lcccc}
\hline \hline & As-is & Insure & Retrofit & Aseismic \\
\hline After-tax net operating income, \$M & $\$ 0.80$ & $\$ 0.75$ & $\$ 0.80$ & $\$ 0.80$ \\
After-tax PV of income, E[I], \$M & 39.0 & 31.5 & 39.0 & 39.0 \\
Purchase price C, , \$M & 10.0 & 10.0 & 12.4 & 10.0 \\
EAL, \$M/yr & 0.050 & 0.033 & 0.043 & \\
After-tax PV of earthquake loss E[L], \$M & 1.48 & 0.99 & 1.29 & \\
Mean after-tax net value E[V], \$M & 27.5 & 20.5 & 25.3 & 29.0 \\
Variance of income Var[I] & 1521.0 & 1521.0 & 1521.0 & 1521.0 \\
Variance of loss Var[L] & 0.908 & 0.717 & 0.702 & \\
Variance of value Var[V] & 1521.91 & 1521.72 & 1521.70 & 1521.00 \\
Certainty equivalent CE, \$M & 19.9 & 12.9 & 17.7 & 21.4 \\
\hline \hline
\end{tabular}

The $E A L$ of $\$ 50,000$ per year, for example, is equivalent to the salary and benefits of one or more employees - a significant expense that the typical investor would not ignore.

\section{JAPANESE DEMONSTRATION BUILDINGS}

Three Japanese demonstration buildings are used. Building 1, illustrated in Figure 11, is a 9-story, 388,000-square-foot, steel-reinforced-concrete structure built in 1961 and designed according to the 1950 building code. It is evaluated under as-is and retrofitted condition. (The retrofitted version is referred to here as Building \#2; the retrofit is a structural upgrade to comply with the Seismic Rehabilitation Standard.) Building \#3 (Figure 12) is a premier-class 29-story high-rise, 958,000-square-foot steel frame building. See Table 3 for summary features. Market value is analyzed using the versatile Kajima-D software.
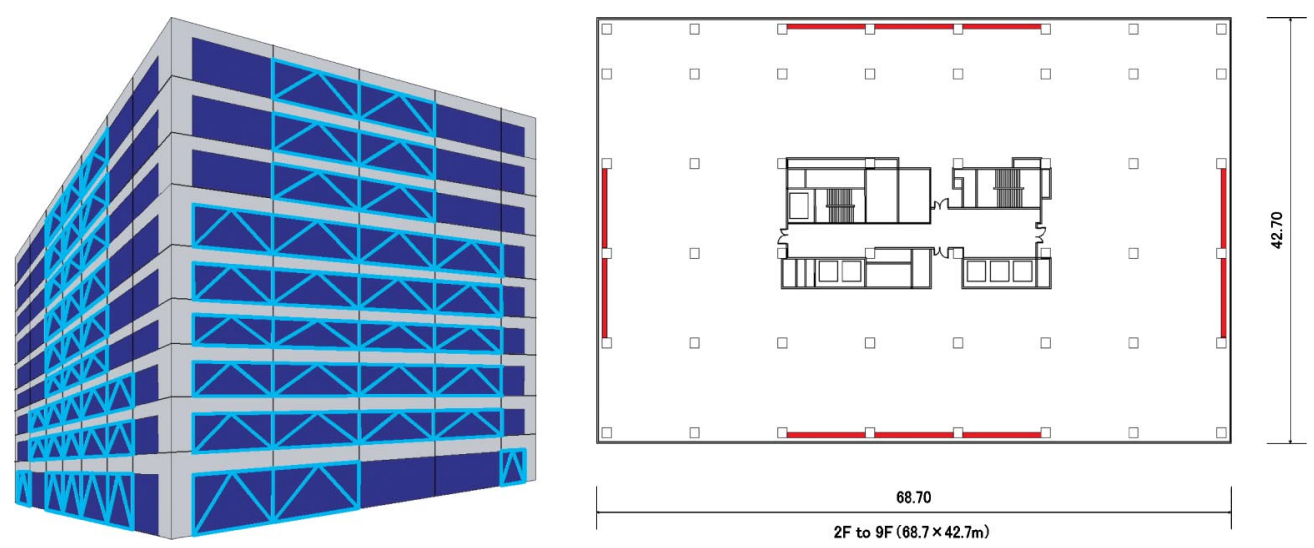

Figure 11. Japanese demonstration buildings 1 (without braced frames) and 2 (with braced frames): elevation and typical floorplan. 

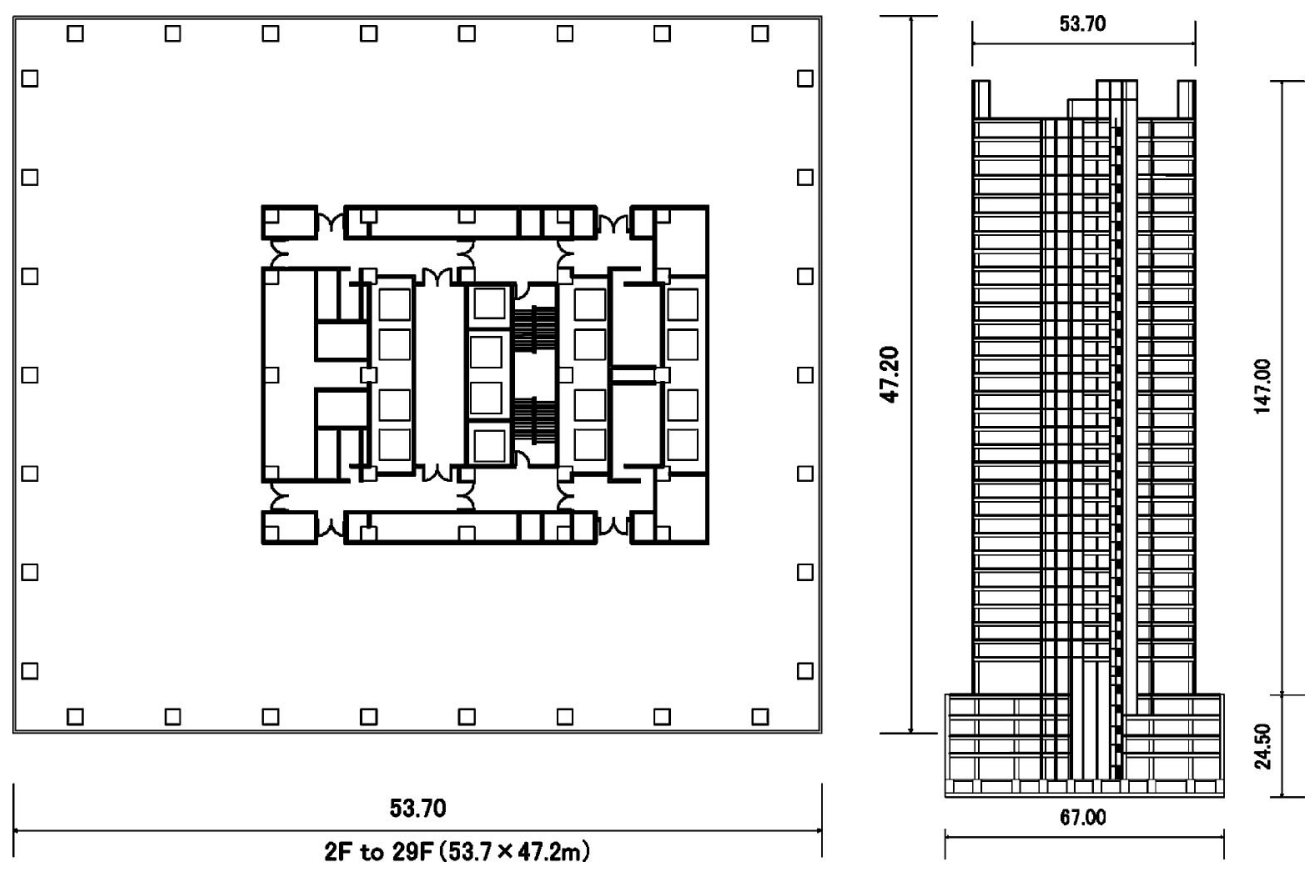

Figure 12. Japanese demonstration building 3 plan and section.

All three buildings are analyzed for a site in Tokyo, at $35.675^{\circ} \mathrm{N}, 139.771^{\circ} \mathrm{E}$, near the JR Tokyo railway station, one of the most prominent commercial areas in Japan. The seismic hazard for this site is quantified considering two types of seismic source: the Kanto earthquake and background seismicity. The seismogenic-zone model for the background seismicity is taken from a 1994 CUREe-Kajima study of the seismic hazard for

Table 3. Summary of Japanese demonstration buildings

\begin{tabular}{lccc}
\hline \hline & Building \#1 & Building \#2 & Building \#3 \\
\hline Class & $\mathrm{B}$ & $\mathrm{A}$ & Premier \\
Seismic performance & Low & Medium & Very high \\
Year built & 1961 & $1961^{*}$ & 1999 \\
Stories & $9 \mathrm{~F} / \mathrm{B} 3 / \mathrm{P} 2$ & $9 \mathrm{~F} / \mathrm{B} 3 / \mathrm{P} 2$ & $29 \mathrm{~F} / \mathrm{B} 4 / \mathrm{P} 2$ \\
Floor area & $388,000 \mathrm{sf}$ & $388,000 \mathrm{sf}$ & $958,000 \mathrm{sf}$ \\
Site area & $38,000 \mathrm{sf}$ & $38,000 \mathrm{sf}$ & $81,000 \mathrm{sf}$ \\
Rentable area & $269,000 \mathrm{sf}$ & $269,000 \mathrm{sf}$ & $667,000 \mathrm{sf}$ \\
Parking spaces & 50 & 50 & 150 \\
Construction & SRC & SRC & $\mathrm{S}$ \\
Replacement cost & US\$73.0M & US\$73.0M & US $\$ 254.0 \mathrm{M}$ \\
Retrofit cost & & US\$7.2M & \\
\hline \hline
\end{tabular}

* Hypothetical 1999 seismic retrofit 

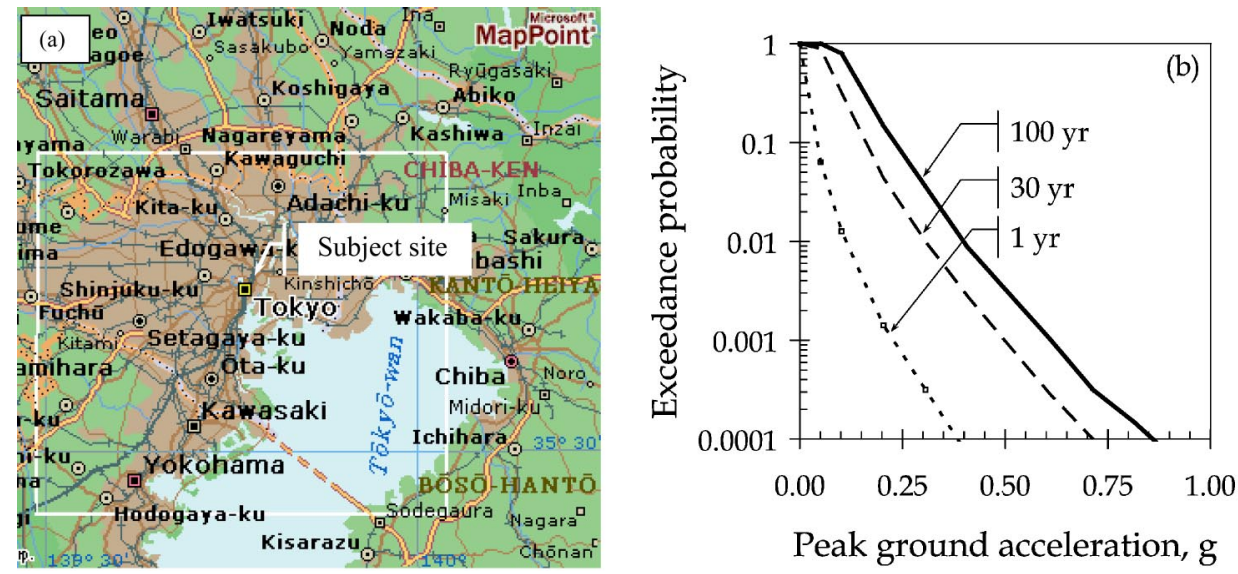

Figure 13. (a) Location and (b) site hazard of Japanese demonstration buildings.

Akasaka, Tokyo. This model consists of 13 zones, but it was found that the zone just beneath Tokyo dominates the hazard for this site. The attenuation equation by Takahashi et al. (1998) was used, with a logarithmic standard deviation of 0.5 . The site location and resulting hazard relationships are shown in Figure 13.

A method akin to $\mathrm{ABV}$ was used to assess the seismic vulnerability functions of the three Japanese buildings. Referred to as Kajima Level-3 analysis, it is a semi-assemblybased approach that consists of subdividing a building into components, estimating the response of these components for given ground motions, and estimating the vulnerability of each component separately. The overall vulnerability of the structure is obtained by combining the vulnerability of all the components into a single-value weighted building vulnerability.

In this method, rather than estimating structural responses by running a large number of dynamic analyses, a linear interpolation is adopted to estimate responses based on the response results at intensity levels of earthquakes that usually correspond to peak ground velocities of $25 \mathrm{~cm} / \mathrm{sec}$ and $50 \mathrm{~cm} / \mathrm{sec}$. Response uncertainty is taken from tables of coefficients of variation that are based on literature reviews and empirical data. It is assumed that the response quantities are perfectly correlated. The uncertainty associated with the component vulnerability curves is ignored and only the mean vulnerability curves are used to estimate component damage. The resulting whole-building mean vulnerability functions are shown in Figure 14a. The cumulative contribution to $E A L$ for building 1 from various increasing levels of shaking is shown in Figure 14b; note its similarity to Figure $9 \mathrm{~b}$.

The risk profiles for the three Japanese demonstration buildings are given in Table 4 . Note that the $E A L$ values are of the same order as the U.S. building, which under the as-is case has an $E A L$ of $0.5 \%$ of purchase price and $0.8 \%$ of building replacement cost. Thus the same conclusions from the U.S. demonstration building apply to the Japanese cases. 

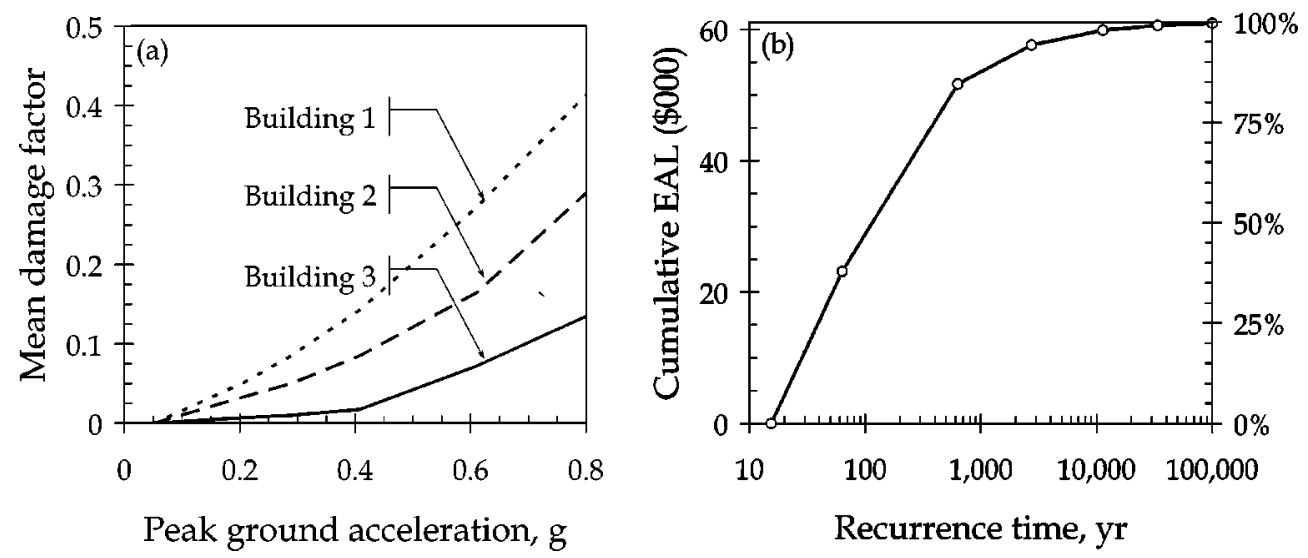

Figure 14. (a) Mean seismic vulnerability functions for Japanese demonstration buildings, and (b) dominance of frequent events in $E A L$ for building 1.

\section{CONCLUSIONS}

We can draw at least five meaningful conclusions from the methodology and case studies presented here.

1. Seismic risk matters in the mean. For all of the demonstration buildings studied here, seismic risk produces a modest mean reduction in NAV and an $E A L$ that would represent a noticeable expense to the investor, if it were accounted for in the financial analysis.

2. Uncertainty in seismic risk does not matter. Uncertainty in future rental rates, vacancy rates, and other market parameters dominate uncertainty in value. One can ignore uncertainty in earthquake repair costs for purposes of real estate investment decision making. Nonetheless, uncertainty in the present value of future earthquake repair costs is of interest in other domains, and we have presented a method for calculating the higher moments of these discounted costs.

3. One can account for seismic risk using standard financial analysis. If one

Table 4. Summary of risk profile of Japanese demonstration buildings

\begin{tabular}{cccc}
\hline \hline \multirow{2}{*}{$\begin{array}{c}\text { Annual exceedance } \\
\text { probability }\end{array}$} & \multicolumn{3}{c}{ Loss (\% of property value) } \\
Bldg. \#1 & Bldg. \#2 & Bldg. \#3 \\
\hline $2.0 \%$ & 4.5 & 3.0 & 0.6 \\
$0.5 \%$ & 9.7 & 5.3 & 1.0 \\
$0.2 \%$ & 14.7 & 8.4 & 1.7 \\
$0.1 \%$ & 19.7 & 11.7 & 3.7 \\
EAL & 1.14 & 0.69 & 0.15 \\
\hline
\end{tabular}


can generate expected annualized loss $(E A L)$, it can be included in a standard financial analysis as an operating expense. Alternatively, one can base the purchasing decision on certainty equivalent $(C E)$. The challenge in either case is to generate the seismic vulnerability function and the hazard function or to use a simplified technique (Porter et al. 2004-this issue) to estimate EAL.

4. PML is of little value to investors. While PML is a serious matter to U.S. and Japanese investors and lenders, investors have little use for the $P M L$ other than to satisfy lenders, because of its excessively long return period and irrelevance in standard financial analysis, and because standard practice does not require its disclosure or treatment. An alternative performance metric, the probable frequent loss $(P F L)$, is proposed in a companion study by Porter et al. (in this issue). It is defined as the mean loss conditioned on a more frequent event such as shaking with $10 \%$ exceedance probability in 5 years - a reasonable upperbound loss in a reasonable planning period.

5. Moderate shaking contributes most of the economic seismic risk. For the relatively vulnerable U.S. demonstration building, EAL is dominated by losses from frequent events, with $50 \%$ contributed by events with $S_{a} \leqslant 0.3 \mathrm{~g}$, and mean return periods of $\mathrm{T} \leqslant 80 \mathrm{yr}$. Similar results are found for the Japanese building \#1. One implication is that the PFL could be realistically calculated using linear structural analysis. (See the companion study, Porter et al. 2004 [in this issue], for treatment of this topic, in which it is shown that, at least in the case of the U.S. demonstration building, $E A L$ can be estimated as a factor $H$ times $P F L$, where $H$ is a function solely of hazard.)

\section{ACKNOWLEDGMENTS}

This research was funded by the CUREE-Kajima Joint Research Program, Phase IV, whose support is gratefully acknowledged. Thanks also to Mr. John Machin of Ray Young Associates, who provided professional cost-estimation services. A number of investors and decision makers contributed their time during our exploration of risk attitude. For anonymity's sake, we cannot thank them by name, but their help is appreciated.

\section{REFERENCES}

American Society for Testing and Materials (ASTM), 1999. E 2026-99 Standard Guide for the Estimation of Building Damageability in Earthquakes, West Conshohocken, PA, 24 pp.

Ang, A. H. S., Der Kiureghian, A., Fillippou, F., Pires, J., and Polak, E., 1996. Reliability-Based Optimal Aseismic Design of Reinforced Concrete Buildings, Consortium of Universities for Research in Earthquake Engineering, Richmond, CA.

Beck, J. L., Porter, K. A., Shaikhutdinov, R., Au, S. K., Mizukoshi, K., Miyamura, M., Ishida, H., Moroi, T., Tsukada, Y., and Masuda, M., 2002. Impact of Seismic Risk on Lifetime Property Values, Final Report, Consortium of Universities for Research in Earthquake Engineering, Richmond, CA, http://resolver.caltech.edu/caltechEERL:2002.EERL-2002-04.

Byrne, P., and Cadman, D., 1984. Risk, Uncertainty, and Decision-making in Property Development, Cambridge University Press, Cambridge, Great Britain, 182 pp.

Frankel, A., and Leyendecker, E.V., 2001. Uniform Hazard Response Spectra and Seismic Hazard Curves for the United States, CD-ROM, U.S. Geological Survey, Menlo Park, CA. 
Holland, A. S., Ott, S. H., and Riddiough, T. J., 2000. The role of uncertainty in investment: An examination of competing investment models using commercial real estate data, Real Estate Economics 28, 33-64.

Howard, R. A., and Matheson, J. E., 1989. Readings on the Principles and Applications of Decision Analysis, Strategic Decisions Group, Menlo Park, CA.

International Code Council (ICC), 2000. 2000 International Building Code, International Conference of Building Officials, Whittier, CA, $756 \mathrm{pp}$.

Islam, M. S., 1996a. Analysis of the response of an instrumented 7-story nonductile concrete frame building damaged during the Northridge earthquake, Proceedings of 1996 Annual Meeting of the Los Angeles Tall Buildings Structural Council, May 10, 1996, Los Angeles, $C A$.

Islam, M. S., 1996b. Holiday Inn, 1994 Northridge Earthquake Buildings Case Study Project Proposition 122: Product 3.2, Seismic Safety Commission, Sacramento, CA, pp. 189-233.

Islam, M. S., Gupta, M., and Kunnath, S., 1998. Critical review of the state-of-the-art analytical tools and acceptance criterion in light of observed response of an instrumented nonductile concrete frame building, Proceedings of 6th U.S. National Conference on Earthquake Engineering, Seattle, WA, May 31-June 4, 1998, Earthquake Engineering Research Institute, Oakland, CA.

Jennings, P. C., 1971. Engineering Features of the San Fernando Earthquake of February 9, 1971, Report EERL 71-02, California Institute of Technology, Pasadena, CA.

Kiremidjian, A. S., 1998. Multiple earthquake event loss estimation methodology, Proceedings of 11th European Conference on Earthquake Engineering, Paris, France, 6-11 Sept 1998.

Li, Y. R., and Jirsa, J. O., 1998. Nonlinear analyses of an instrumented structure damaged in the 1994 Northridge earthquake, Earthquake Spectra 14 (2), 245-264.

Papoulis, A., 1991. Probability, Random Variables, and Stochastic Processes, McGraw-Hill, New York, NY.

Porter, K. A., Kiremidjian, A. S., and LeGrue, J. S., 2001. Assembly-based vulnerability of buildings and its use in performance evaluation, Earthquake Spectra 17 (2), 291-312.

Porter, K. A., 2000. Assembly-Based Vulnerability of Buildings and its Uses in Seismic Performance Evaluation and Risk-Management Decision-Making, Ph.D. dissertation, Stanford University, Stanford, CA, and ProQuest Co., Ann Arbor, MI, pub. 99-95274, 196 pp., http:// wwwlib.umi.com/dissertations/preview/9995274.

Porter, K. A., Beck, J. L., and Shaikhutdinov, R. V., 2002. Sensitivity of building loss estimates to major uncertain variables, Earthquake Spectra 18 (4), 719-743.

Porter, K. A., 2003. An overview of PEER's performance-based earthquake engineering methodology, Proceedings of 9th International Conference on Applications of Statistics and Probability in Civil Engineering (ICASP9), July 6-9, 2003, San Francisco, CA, Civil Engineering Risk and Reliability Association (CERRA), http://keithp.caltech.edu/publications.htm.

Porter, K. A., Beck, J. L., and Shaikhutdinov, R. V., 2004. Simplified estimation of economic seismic risk for buildings, Earthquake Spectra 20 (4), 1239-1263 (this issue).

Ratcliff, R. U., and Schwab, B., 1970. Contemporary decision theory and real estate investment, Appraisal Journal, April 1970, reprinted in Cooper, J. R., 1974, Real Estate Investment Analysis, D.C. Heath and Company, Toronto, Canada, pp. 25-47.

Scholl, R. E., Kustu, O., Perry, C. L., and Zanetti, J. M., 1982. Seismic Damage Assessment for High-Rise Buildings, URS/JAB 8020, URS/John A. Blume \& Associates, Engineers, San Francisco, CA, 321 pp. 
Takahashi K., Takemura, M., Tohdo, M., Watanabe T., and Noda, S., 1998. Empirical response spectral attenuations on rock with Vs $=0.5$ to $3.0 \mathrm{~km} / \mathrm{s}$, in Japan, Proceedings of 10th Japan Earthquake Engineering Symposium, Vol. 1, pp. 547-552 (in Japanese).

Tinsley, J. C., and Fumal, T. E., 1985. Mapping Quaternary sedimentary deposits for areal variations in shaking response, Evaluating Earthquake Hazards in the Los Angeles Region-An Earth-Science Perspective, U.S. Geol. Surv. Professional Paper 1360, U.S. Government Printing Office, Washington D.C., pp. 101-126.

Trifunac, M. D., Ivanovic, S. S., and Todorovska, M. I., 1999. Instrumented 7-Storey Reinforced Concrete Building in Van Nuys, California: Description of the Damage from the 1994 Northridge Earthquake and Strong Motion Data, Report CE 99-02, University of Southern California Department of Civil Engineering, Los Angeles, CA.

Von Neumann, J., and Morgenstern, O., 1944. Theory of Games and Economic Behavior, Princeton University Press, Princeton, NJ, 625 pp.

Zadeh, M.M., 2000. Understanding risk management, Financial Management of Earthquake Risk, Earthquake Engineering Research Institute, Oakland, CA, pp. 1-14.

(Received 22 September 2003; accepted 15 March 2004) 